\title{
CAPACITAÇÃO NO USO DA LOUSA INTERATIVA
}

Roberto Douglas da Costa ${ }^{1}$

Tchiang Rodrigues Fong Nien Neto ${ }^{2}$

José Paulo Ribeiro Júnior ${ }^{3}$

Wanderson Modesto da Silva ${ }^{3}$

\section{RESUMO}

O maior desígnio da tecnologia é proporcionar melhorias nas atividades cotidianas. Portanto, este projeto teve como objetivo capacitar professores e profissionais da educação para o uso do quadro interativo ou lousa interativa como recurso tecnológico aplicado no uso educacional, possibilitando à classe educadora um maior dinamismo na explanação dos seus conteúdos em sala de aula. Foram capacitados em torno de trinta profissionais, entre eles servidores do IFRN oriundos de vários Campi, como também um público externo formado por professores da rede pública estadual e municipal do estado do Rio Grande do Norte, os quais servirão de disseminadores dessa tecnologia para capacitação de outros profissionais nas suas instituições de origem.

Palavras chaves: capacitação. Lousa Interativa. Tecnologia.

\section{INTRODUÇÃO}

Em um mundo cada vez mais globalizado, a utilização de novas tecnologias vem desenvolvendo no contexto educacional novas formas de aprendizado, de disseminação do conhecimento e principalmente de relação entre professor e aluno, tornando assim um atrativo para a nova geração que está nos bancos da escola.

Não resta dúvida de que a utilização de novas tecnologias educacionais traz para o ambiente da sala de aula uma nova forma de interação entre os integrantes do processo de ensino e aprendizagem, atendendo, assim, aos anseios e às necessidades de todos os integrantes desse processo, mais especificamente do aluno, trazendo um incentivo à parte a sua aprendizagem.

Nos dias atuais, essa mudança na relação professor e aluno, intermediada pelo uso das novas tecnologias educacionais, é bastante essencial para o processo de ensino e aprendizagem, pois proporciona ao docente uma forma mais direta de interação com o seu aluno, tornando sua aula mais atrativa e participativa.

Conforme Moran (2007), as tecnologias permitem mudanças significativas na educação, mas permanecem geralmente inexploradas pela

1 Professor do IFRN Campus EaD

2 Técnico em Áudio Visual - Campus EaD

3 Alunos do IFRN - Bolsistas do projeto 
inércia da cultura tradicional e pelo medo da inovação. As mudanças na educação dependem não somente das tecnologias, mas de termos educadores, gestores e alunos dispostos a mudanças; maduros intelectual, emocional e eticamente; pessoas curiosas, entusiasmadas, que saibam motivar e dialogar.

\section{OBJETIVOS}

Com o objetivo de proporcionar melhor convivência dos profissionais docentes com novas tecnologias educacionais, tornando conveniente sua aplicação, o Campus de Educação a Distância (EaD) laçou em 2012 o curso de extensão intitulado "Capacitação no uso da Lousa Interativa".

O objetivo maior da tecnologia é proporcionar melhorias nas atividades cotidianas. Por isso, este projeto de extensão teve como foco principal a capacitação dos profissionais da educação na utilização do quadro interativo ou lousa interativa, sendo uma das novas tecnologias aplicadas ao ensino.

Para esse projeto foram ofertadas três turmas. Cada uma delas dispunha de uma carga horária de 20 horas presenciais, sendo 2 horas/aula por dia. Os custos operacionais para esse programa foram disponibilizados para a confecção de apostilas e manutenção do laboratório de informática do Campus EaD utilizado para o exercício das atividades.

Atualmente somente o Campus EaD e o Campus Natal-Central possuem lousas interativas, mas sua utilização efetivamente em sala de aula não está ocorrendo por falta de conhecimentos dos professores com relação a essa tecnologia. Com isso, o curso terá como objetivo central capacitar professores e técnicos administrativos do Campus EaD e do Natal-Central, como também de outros Campi e público externo no uso desse recurso.

\section{METODOLOGIA}

As ações de extensão são entendidas como um processo educativo, cultural e científico que articula o ensino e a pesquisa de forma indissociável para viabilizar a relação transformadora entre o IFRN e a sociedade.

De natureza acadêmica, a extensão constitui-se de uma ação mediadora do processo dialético entre teoria e prática. É capaz de ampliar a formação ou a qualificação profissional de estudantes e de educadores em geral. Como via de interação com a sociedade, constitui-se em um elemento de mão dupla indispensável tanto para o Instituto conhecer a realidade sociocultural, econômica e política do seu entorno, quanto para a comunidade ter acesso ao saber produzido no e pelo Instituto.

O processo de ensino aprendizagem na extensão possui um arsenal metodológico diferenciado, uma vez que acontece por meio de encontros entre alunos, docentes, técnicos administrativos e comunidade, em quem são incorporados outros saberes, criando um novo senso comum e ampliando a capacidade de reflexão sobre as práticas constituídas pelas experiências.

Em sua ação cotidiana, a extensão funciona como um processo de estímulo à produção de conhecimentos, entendimentos e reflexões sobre os problemas e dificuldades vividas pela sociedade na qual a instituição está inserida, objetivando sempre a troca de saberes e conhecimentos, ocasionando a interação entre o fazer acadêmico e o popular, no sentido de estreitar as relações entre a instituição, no nosso caso o IFRN, e a sociedade.

Portanto, no arcabouço da extensão, a educação, a ciência e a tecnologia devem estar articuladas, de modo a agregar saber e fazer, a socializar conhecimentos, a possibilitar trocas de saberes (acadêmicos, experienciais e populares) e a contribuir, à luz de um saber fazer reflexivo e crítico, com o desenvolvimento da práxis profissional.

A metodologia utilizada foi a de aulas expositivas com a utilização da própria lousa interativa para explanação dos conteúdos e a utilização de computadores para cada aluno desenvolver suas atividades. Além do computador, os participantes utilizaram como material didático uma apostila desenvolvida pela equipe de coordenação do projeto, que abordava conceitos e exercícios sobre a ferramenta trabalhada. As fases do desenvolvimento do projeto seguiram uma carga horária definida. Durante esse período, os participantes tiveram a oportunidade de desenvolver tarefas no computador e na lousa interativa e relacioná-las ao seu cotidiano acadêmico.

\section{AÇÕES DESENVOLVIDAS}

As atividades acadêmicas desenvolvidas foram divididas em duas fases, sendo uma teórica e outra prática. Na primeira fase, foram abordados conceitos históricos, observando desde o uso do 
quadro negro, passando pelo quadro de lousa e finalizando na lousa digital.

Ainda na primeira fase, os alunos tiveram o primeiro contato com os recursos da lousa interativa, como os botões, as canetas, o teclado virtual, o recurso de calibração da lousa, dentre outros recursos exibidos pelo professor (figura 1).

Concluindo a primeira fase do curso, os alunos viram a real necessidade e aplicabilidade do uso desse recurso, adequando-o ao planejamento educacional das suas disciplinas.

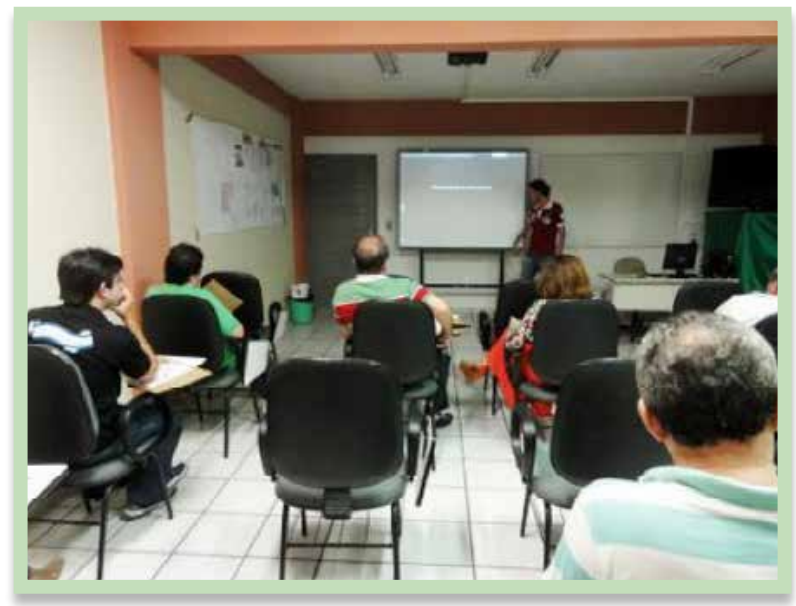

Figura 1: sala de treinamento do Campus EaD Aula da 1a fase

Na segunda fase, a fase prática, os alunos trabalharam com as configurações da lousa, instalação do software e um pouco sobre a manutenção deste recurso.

\section{CONCLUSÃO}

As novas tecnologias educacionais se propõem debater as possibilidades que essas ferramentas tecnológicas oferecem para 0 surgimento de novos padrões de aquisição e de construção de conhecimento, ao permitir o uso integrado e interativo de diversas mídias. Pensando nessa interatividade, foi que surgiu este projeto de capacitação do uso da lousa interativa, um novo recurso tecnológico que o professor poderá usar em sala com intuito de dinamizar suas aulas, permitindo a abordagem de seus conteúdos de forma mais atrativa para seus alunos, induzindo-os ao ambiente da sala de aula.

Neste projeto foram capacitados em torno de trinta profissionais da educação, incluindo professores, coordenadores pedagógicos e técnicos administrativos em educação, sendo eles profissionais do IFRN e também público externo composto por professores da rede pública de ensino estadual e municipal. Esses profissionais habilitados por meio deste curso servirão de divulgadores em seus estabelecimentos de ensino de origem para capacitação de novos professores na utilização desse novo recurso educacional.

\section{REFERÊNCIAS}

MORAN, José Manuel. Desafios na comunicação pessoal. 3. ed. São Paulo: Paulinas, 2007.

IFRN. Resolução no 66/2009-IFRN. Disponível em: <http://portal.ifrn.edu.br/conselhos/consup/ resolucoes/resolucoes-2009/066_Aprovar\%20 Ad\%20Referendum\% 200\%20Estatuto\%20do\%20 IFRN.pdf/view>. Acesso em: 03 ago. 2014. 